\title{
Simultaneous hot and cold thyroid nodules: Which is malignant?
}

\author{
Yuki Otsuka $^{1}$ (D) | Yasuhiro Nakano ${ }^{1}$ | Daisuke Omura ${ }^{1}$ (D) | Takayuki Iwamoto $^{2}$ | \\ Ruiko Hayashi $^{3}$ | Fumio Otsuka ${ }^{1}$
}

${ }^{1}$ Department of General Medicine, Okayama University Graduate School of Medicine, Dentistry and Pharmaceutical Sciences, Okayama, Japan

${ }^{2}$ Department of Breast and Endocrine Surgery, Okayama University Hospital, Okayama, Japan

${ }^{3}$ Department of Internal Medicine, Kosei General Hospital, Mihara, Japan

\section{Correspondence}

Yuki Otsuka, Department of General Medicine, Okayama University Graduate School of Medicine, Dentistry and Pharmaceutical Sciences, 2-5-1 Shikatacho, Kita-ku, Okayama 700-8558, Japan. Email: otsuka@s.okayama-u.ac.jp

\begin{abstract}
Physicians should be aware of the risk of malignancy in patients with toxic multinodular goiter. Radionuclide scan cannot be used to predict the malignant potential of thyroid nodules. A comprehensive evaluation of imaging studies is needed.
\end{abstract}

\section{K E Y W O R D S}

autonomous functioning thyroid nodule, hyperthyroidism, thyroid papillary cancer, toxic multinodular goiter

\section{1 | CASE DESCRIPTION}

A 53-year-old woman, treated with $10 \mathrm{mg}$ of thiamazole for postoperative recurrence of hyperthyroidism, was referred to our department for further investigation of a neck goiter. The patient's thyroid function was free T3: $2.64 \mathrm{pg} / \mathrm{mL}$ (normal range: $2.30-4.00 \mathrm{pg} / \mathrm{mL})$, free T4: $0.80 \mathrm{ng} / \mathrm{dL}(0.97-1.69 \mathrm{ng} /$ $\mathrm{dL})$, and TSH: $3.73 \mathrm{U} / \mathrm{mL}(0.33-4.05 \mathrm{U} / \mathrm{mL})$. TSH receptor antibodies (TRAb) were negative. However, the serum thyroglobulin level was elevated to $982 \mathrm{ng} / \mathrm{mL}$ (normal range: $<33.7 \mathrm{ng} / \mathrm{mL}$ ). Echocardiography revealed bilateral isoechoic nodules surrounded by low-echoic lesions. Tc-99m scintigraphy showed a hot nodule in the left lobe that was consistent with a functional nodule, in addition to a cold nodule in the right lobe (Figure 1A). Pathological examination after subtotal thyroidectomy revealed a right papillary carcinoma (Figure 1B) and a left adenomatous nodule (Figure 1C).

Toxic multinodular goiter (TMNG) refers to typically benign nodules in the thyroid gland that autonomously secrete excessive amounts of thyroid hormones, and it is one of the primary causes of hyperthyroidism or thyrotoxicosis. Up to $15 \%$ of patients with nodules have neoplastic changes. ${ }^{1}$ TMNG may be characterized by a mixture of functional and nonfunctional adenomas. A radionuclide scan is useful for identifying the functional status of these nodules. Hot nodules are hyperfunctioning nodules, while cold nodules indicate defects in secretory function. Coincidental carcinomas with TMNG have been rarely reported; whereas a recent study revealed that hot and cold nodules have the same risk of malignancy. ${ }^{2}$ Therefore, diagnosis should not be based solely on radionuclide images. Physicians should recognize that the most suitable treatment for MTNG is surgical excursion and consider the possibility of malignancy by comprehensive evaluation of imaging studies.

\section{CONFLICT OF INTEREST}

The authors declare no conflicts of interest in association with this study. 


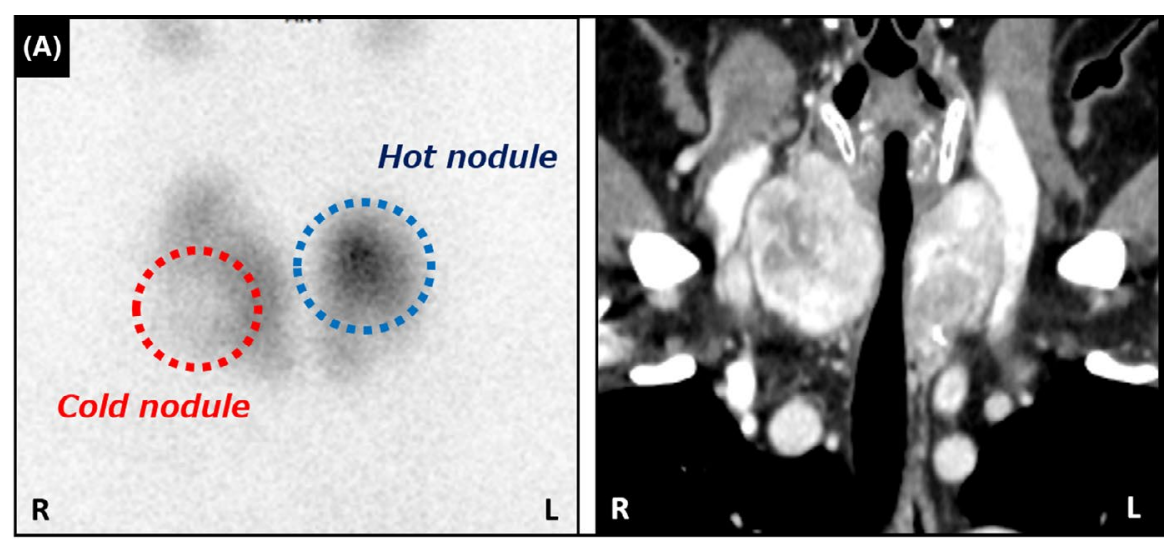

FIG URE 1 Tc-99m scintigraphy showed both a hot nodule and a cold nodule (A). The right cold nodule was pathologically diagnosed as papillary cancer (B), and the left hot nodule was diagnosed as an adenomatous goiter (C)
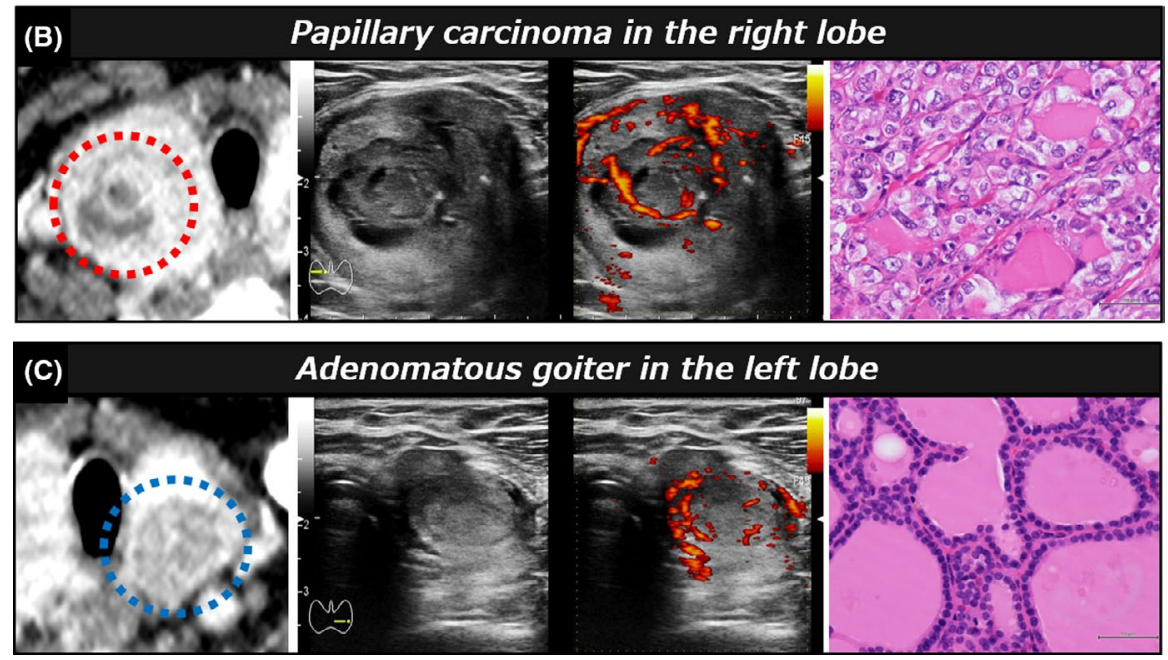

\section{AUTHORS' CONTRIBUTION}

YO: contributed to the clinical management of the patients, wrote the first draft, and managed all the submission process. YN, DO, TI, RH, and FO: contributed to the clinical management of the patient and revised the manuscript.

\section{DATA AVAILABILITY STATEMENT}

The data regarding this case report are only available from the corresponding author upon reasonable request by considering the protection of patient's privacy.

\section{ORCID}

Yuki Otsuka (D) https://orcid.org/0000-0001-6015-6128 Daisuke Omura (D) https://orcid.org/0000-0002-7878-3813 Fumio Otsuka (D) https://orcid.org/0000-0001-7014-9095

\section{REFERENCES}

1. Luo J, McManus C, Chen H, Sippel RS. Are there predictors of malignancy in patients with multinodular goiter? J Surg Res. 2012;174(2):207-210.

2. Baser H, Topaloglu O, Bilginer MC, et al. Are cytologic and histopathologic features of hot thyroid nodules different from cold thyroid nodules? Deagn Cytopathol. 2019;47(9):898-903.

How to cite this article: Otsuka Y, Nakano Y, Omura D, Iwamoto T, Hayashi R, Otsuka F. Simultaneous hot and cold thyroid nodules: Which is malignant? Clin Case Rep. 2021;00:1-2. https://doi.org/10.1002/ $\underline{\mathrm{ccr} 3.3843}$ 